\title{
O cientista, o jornalista e o assessor. Uma análise dos embates, dos limites e das possibilidades de construção de um possível diálogo
}

\author{
Boanerges Balbino Lopes Filho \& Wedencley Alves \\ Universidade Federal de Juiz de Fora \\ E-mail: bblopes@globo.com/ wedencley@gmail.com
}

\begin{abstract}
Resumo
Os processos de comunicação são atualmente pensados, nos estudos de mídia, como espaços de disputas. Envolvem mediações comunicacionais a partir de demandas individuais e de grupos, com a utilização e apoio das tecnologias e redes, cada vez mais autônomas em relação aos centros originários. Os diversos atores envolvidos nas arenas informacionais se relacionam produzindo avanços e recuos, fricções e alianças, acordos e desacordos, hegemonias e contra-hegemonias discursivas, polarizando assim o denominado poder simbólico. Assim, organizações - empresas, entidades, associações, governos etc. - precisam usar este espaço para tornar visíveis suas ações, ao mesmo tempo em que buscam a legiti-

midade junto à imprensa. Neste artigo, tratamos da relação entre imprensa, pesquisadores e instituições científicas. Se jornalistas reclamam da pouca disposição dos cientistas em repassar-lhes as informações solicitadas, pesquisadores desconfiam do que será publicado em seus nomes. Se jornalistas ou cientistas estão certos em suas queixas e desconfianças, nunca saberemos. Mas uma questão pode nos ajudar a discutir o problema: "As estratégias de comunicação praticadas pelas organizações - especialmente instituições de saúde - têm contribuído de alguma forma para uma boa divulgação científica e incrementado o aumento da qualidade de vida da sociedade"?
\end{abstract}

Palavras-Chave: Comunicação; ciência, divulgação; relacionamento; diálogo.

\begin{abstract}
The communication process is thought at present, in media studies, as place of disrequirements with the use and support putes. It involves individual and group gly independent from its original centers.
\end{abstract}


The relationship among various actors makes, at informational arenas, progresses and retreats, frictions and alliances, agreements and disagreements, discursive hegemony and counter-hegemony, polarizing the so-called symbolic power. Thus, organizations - companies, institutions, associations, governments etc. need to use this place to make visible their actions, while they search legitimation on the media. In this paper, our aim is to understand the relationship among the press, researchers and scientific insti- tutions. While the journalists complain about the unwillingness of scientists to pass them the information required, researchers are wary of what will be published in their names. We shall never know if journalists or scientists are right in their complaints or distrust, but a question helps us to discuss the subject: "Communication strategies practiced by organizations - especially, heath institutions - have contributed to a good popular science, and magnifying and increasing society's quality of life?"

Keywords: Communication; science, disclosure; relationship; dialogue.

\title{
Introdução
}

\begin{abstract}
relação entre imprensa e instituições de saúde suscita questionamentos A tanto de um lado quanto de outro. Jornalistas reclamam da pouca disposição dos profissionais de saúde em atender os meios e repassar informações mais amplas quando solicitadas. Médicos, pesquisadores, entre outros, desconfiam do que será publicado em seu nome. Independentemente dos dois lados terem ou não razão em suas queixas, uma terceira indagação, menos corporativa e mais afinada com os anseios da população, deve ser feita: "as estratégias de comunicação utilizadas pelas diversas empresas e instituições que atuam nas duas áreas têm contribuído de alguma forma para o aumento da qualidade de vida do cidadão?
\end{abstract}

\section{Referências}

Responder a esta questão e mais algumas outras deve estar na agenda de quem está preocupado efetivamente com as necessidades da sociedade na área de saúde. É evidente que não podemos negar as dificuldades de superação da distância - de estilos, de interesses, de rotinas de trabalho, de visões de mundo - entre os profissionais, distâncias que foram e são alimentadas visivelmente 
O cientista, o jornalista e o assessor. Uma análise dos embates, dos limites e das possibilidades de construção de um possível diálogo

a cada dia, contribuindo para aumentar o sofrimento e as dificuldades da população brasileira. Ou seja: tanto o campo da saúde, quanto o campo da mídia estão em débito com a sociedade.

E as dívidas são altas. Pesquisa realizada pelo instituto Datafolha mostrou que, para um grande contingente populacional, o principal problema das grandes cidades brasileiras é justamente o estado permanente de crise na saúde pública. No final de 2008, 28\% dos entrevistados apontavam o setor como o mais preocupante. No início de 2011, o número foi a $31 \%$. E, em janeiro, o índice de preocupação chegaria a 39\%. Ainda que o instituto de pesquisa jogue claramente a culpa num só agente, os governos, é claro que algo está errado também na cobertura de imprensa, como veremos mais adiante.

Três são as questões levantadas neste artigo, e três são as tentativas de responder a elas: quais os embates mais freqüentes entre imprensa e instituições de saúde? Quais os limites tanto discursivos quanto institucionais que há entre a cobertura jornalística e as práticas da saúde? Qual o perfil mais apropriado do assessor de comunicação e de imprensa, profissional que poderia fazer a mediação mais capacitada entre uns e outros?

\section{Território de embates}

A preocupação da população, demonstrada pelo instituto Datafolha, não está dissociada da realidade. É que, apesar de alguma evolução, as estatísticas ainda acentuam aspectos dramáticos da saúde pública no Brasil ${ }^{1}$. Infelizmente os dados desse "diagnóstico" parcial quando divulgados - em raros momentos - são fragmentados pelos principais jornais, revistas, rádios e tevês. As coberturas nesta área acabam em editorias diferentes. Textos dispersos, além de manchetes, títulos, legendas e fotos alarmantes reforçam preconceitos e mitos. As reações vão da perplexidade ao pânico. Mas de concreto, pouco se resolve.

1. Só para ficar no exemplo da saúde básica. Embora tenha passado a integrar o grupo de países com alto Índice de Desenvolvimento Humano (IDH), o país ainda convive com números muito preocupantes: em relação, ao tratamento de esgoto, por exemplo, $57 \%$ da população brasileira ainda não têm acesso a este serviço, e do que é coletado só 1/3 é tratado, segundo o levantamento disponibilizado pelo Sistema Nacional de Informações sobre Saneamento, um acompanhamento anual realizado pelo Ministério das Cidades. Um número tão alto de desassistidos não terá outra consequência se não a de provocar uma sobrecarga insuportável sobre o atendimento público de saúde. 
Por outro lado, a maioria dos governantes e administradores da saúde pública, por motivos políticos, e profissionais de saúde, por zelo com relação aos seus nomes, sente-se desconfortável em relação à cobertura quase sempre alarmista da imprensa. Exemplos não faltam: em 2010, uma pesquisa para a Faculdade de Saúde Pública da Universidade de São Paulo mostrou que a epidemia de febre amarela foi "construída" pela imprensa (Malinverni, 2011); outra, desta vez, na Fundação Oswaldo Cruz, demonstrou que o intertexto político prevaleceu na cobertura sobre a H1N1 (Neves, 2012).

Seja exagerando, seja atribuindo sentidos que têm pouco a ver com esclarecimentos à população, a imprensa acaba conquistando a desconfiança, não somente dos governos, mas também dos profissionais do campo da saúde. $\mathrm{O}$ resultado é que os administradores e os profissionais da saúde pública, por motivos políticos ou de auto-preservação, acabam também estimulando, com seu distanciamento, a criação de uma narrativa jornalística, por vezes voltada mais à especulação e menos á informação sobre a realidade. Se as fontes se preservam, é a informação que sai em prejuízo.

E nesse caso onde entra o interesse público? Acaba perdido num emaranhado de disputa de poder e barganhas. Idealmente, seria preciso estabelecer uma correta parceria entre profissionais de saúde e de imprensa, melhorando as práticas de comunicação entre ambos e forçando o poder público a criar novos mecanismos capazes de imprimir-lhe clareza indiscutível que se contraponha ao clientelismo e à utilização do estado em benefício de interesses cartoriais.

Mas este "ideal" parece se deparar com obstáculos maiores que os jogos de projeção imaginária que uns sustentam contra outros (jornalistas, vistos como "deturpadores e sensacionalistas" para os responsáveis pela saúde; estes, como "dissimulando informações", para os jornalistas). Estes obstáculos parecem remeter a diferenças discursivas e institucionais, se não intransponíveis, pelo menos difíceis de serem superadas, se não se buscar uma compreensão do funcionamento das instituições e dos discursos do campo da mídia e do campo da saúde.

Neste fogo cruzado, é justamente o profissional de comunicação especializado em saúde, que talvez pudesse sanar tanta diferença. 
O cientista, o jornalista e o assessor. Uma análise dos embates, dos limites e das possibilidades de construção de um possível diálogo

\section{Limites e possibilidades: questões institucionais e discursivas}

Comecemos com algumas possibilidades, a partir do fenômeno da midiatização das esferas sociais.

O processo de publicização pela mídia dos discursos sociais não pode ser visto somente com uma incorporação in natura dos sentidos circulantes na sociedade, mas um reprocessamento destes discursos, o que provoca deslocamentos a serem considerados por quem se debruçar sobre as questões da educação para a saúde, e que dedique especial atenção ao papel da mídia.

Isto não reafirma qualquer intenção, muito comum no campo das comunicações, de acreditar que sentidos sociais originam-se na imprensa ou na mídia em geral. Parte-se do pressuposto de que há um contínuo processo de vocalização e silenciamentos de discursos já presentes na sociedade, mas cujo processo é, devido às formas de textualização propriamente midiáticas, o de redefinição lógica destes discursos.

Isso é facilmente visto nas discussões acerca da espetacularização dos fatos relacionados à saúde, um fenômeno próprio do sistema de mídias na contemporaneidade. Ao se autorizar, por exemplo, como meio de divulgação científica em saúde, a mídia contribui necessariamente para alterar e não simplesmente promover a imagem do campo da saúde. Ora, se a imagem do que seja a saúde muda conforme as circunstâncias históricas e as expectativas sócio-culturais, é pelo menos razoável deduzir que tamanha interferência vai levar a conseqüências ainda não dimensionadas, mas de antemão bastante importantes para como a sociedade compreende a saúde numa sociedade midiatizada.

Estamos falando aqui da midiatização simétrica do campo da saúde: sua passagem pela mídia ao mundo dos comuns, mas também sua própria estruturação midiática. Isso faz com que a própria medicina, por exemplo, passe por uma forte adesão a suportes de mídia - vídeo-cirugias, uso das redes para transmissão de conferências, exames, procedimentos terapêuticos, blogs escritos por médicos.

É preciso compreender, por exemplo, que o leitor atual, ao se deparar com a midiatização do campo da saúde, e com uma medicina midiatizada, tende a valorizar aquilo que atende à linguagem e discursividade própria aos meios de comunicação. O que, por efeito, vai resultar no fato de que os processos de 
identificação do sujeito com a medicina - e, portanto, com as informações dela procedentes - podem estar atravessadas por elementos da cultura dos media.

O maior sintoma desses atravessamentos é o fato de que coberturas sistemáticas sobre um assunto de saúde em especial, acaba movendo a agenda das preocupações da sociedade. Personagens da vida pública acometidas pelo câncer produzem um maior interesse pela doença, assim como os perfis magérrimos de mulheres modelos podem levar a gerações de menina a rejeitarem uma alimentação adequada.

Ao mesmo tempo, o próprio processo de midiatização, pelos deslocamentos de sentido supracitados, pode trazer problemas para a apreensão do conhecimento sobre a saúde por parte da população em geral: como a busca pela informação que provoque mais comoção e mais atração e o esquecimento de problemas mais básicos, mas que têm consequiências profundas sobre a saúde da sociedade, como é o caso das carências do saneamento básico - que não dão notícia nem votos.

A midiatização da sociedade, estabelecendo um continuum entre a linguagem dos meios de comunicação e as ações institucionais, portanto, podem contribuir para estreitar as distâncias entre a compreensão do público em geral e dos cientistas. Isto é uma possibilidade positiva. Mas, ao mesmo, tempo, se não vista com responsabilidade pela sociedade, pode simplesmente transformar a ciência num picadeiro, para notícias sensacionais, e práticas espetaculares.

Abre-se espaço neste momento para a comunicação institucional, como um lugar de elaboração e reelaboração dos sentidos midiatizados no campo da saúde, uma grande possibilidade de intervenção positiva. Idealmente, a atividade seria exercida ou gerida por um profissional que conhecesse muito bem a linguagem própria da mídia e os meandros complexos de um campo como o da saúde. Um profissional que conseguiria, dado o processo de midiatização social, explorar as possibilidades e evitar os riscos postos por este mesmo processo.

Mais que mediador, ele poderia ser aquele profissional capaz de esclarecer a própria imprensa sobre os riscos sociais de sua cobertura. Exemplos podem ser citados neste momento: as notícias divulgadas sobre a dengue em algumas regiões do país abalaram a indústria do turismo provocando demissões de profissionais da área, devido ao tratamento inadequado das informações. $\mathrm{E}$ os retratos que os meios de comunicação apresentam sobre os pacientes in- 
O cientista, o jornalista e o assessor. Uma análise dos embates, dos limites e das possibilidades de construção de um possível diálogo

ternos em hospitais psiquiátricos em geral são extremamente negativos, não contribuindo em nada para a modificação do quadro.

Ou seja, prejuízos sociais ou individuais causados por falta de preparo profissional e responsabilidade institucional da imprensa, mas que, por outro lado, receberam e recebem muito pouca atenção por parte de especialistas, por administradores e, é claro, pelo poder público.

\section{A mediação entre a instituição de saúde e a imprensa}

Se pelo lado da Imprensa, as posturas não têm sido muito satisfatórias, no denominado lado de cá, ou seja, os representantes da área de saúde, as falhas também são muitas. E quem acaba no meio deste fogo cruzado é justamente o assessor de comunicação social. Quando chamado a intervir, defronta-se normalmente com uma situação já definida - geralmente de crise - e com determinações prontas: 'precisamos é de uma campanha', 'temos que responder à Imprensa desta ou daquela forma' ou 'vamos organizar um evento' é o que ouvimos com tanta frequiência.

É uma situação imposta que normalmente limita-se a ações tópicas e localizadas, o que normalmente denominamos como "apagar incêndios". O ex-diretor de Comunicação Social da Secretaria Estadual de Saúde de Minas Gerais, João Paulo Pinto da Cunha, deixou registrado, num artigo sobre o assunto, já em 1994, no jornal do Radis (Fiocruz), o seguinte desabafo:

Geralmente o responsável pela comunicação recebe uma encomenda definida em termos de público, estratégia e mensagem. Cabe apenas executar. Esta concepção mostra um desrespeito duplo, pela comunicação e pelo profissional. Ainda que não seja uma ciência, a comunicação é, no mínimo, uma técnica com um grande e sofisticado arsenal de intervenção na realidade e no imaginário das pessoas e dos grupos. O comunicador, por sua vez, deve dominar os elementos que lhe deem conhecimento das linguagens, da circulação das mensagens e do mundo de significações dos diferentes públicos. Se o pedido de uma campanha já chega embalado, carimbado e com destino certo, perde-se o potencial da comunicação e do comunicador. (Cunha, 1994)

Quanto mais nos aprofundamos nos assuntos que envolvem a área de saúde, as crises se sucedem: financiamentos, regulamentações das políticas, 
organização de modelos e muitos outros problemas. É neste contexto que a comunicação cada vez mais tem uma enorme contribuição a dar. Sua absorção pelas políticas públicas é uma necessidade premente. E sua concepção deve trilhar por outros caminhos, mais abrangentes.

Os serviços de saúde possuem características próprias que normalmente os diferenciam de outras organizações. Os usuários nem sempre têm informações para avaliar e definir suas necessidades e as maneiras mais adequadas de atendê-las. Os resultados também são de difícil mensuração, sobretudo nos casos mais complexos.

Além disso, a organização dos serviços tem uma dimensão ética e moral bem própria com situações delicadas da biomédica, envolvendo sigilo, direito do usuário à informação e mais uma ampla estrutura administrativa e alocação atípica de recursos. Acreditar que tanto profissionais de imprensa quanto de saúde poderiam entender detalhadamente todo este processo é criar uma falsa expectativa. Assim também como é falso definir o espaço de atuação do comunicador da área de saúde somente pelos contatos com a grande imprensa em casos determinados ou com a dinâmica rotineira de produção de clippings e outros instrumentos utilizados dentro de um setor de assessoria de comunicação. Insistir nestas práticas é deixar de entender o seu verdadeiro papel e limitar o seu potencial.

Os objetivos de uma assessoria de comunicação são e devem ser mais ambiciosos: sempre em mão dupla, identificando os anseios da 'população com informações objetivas, precisas e claras e proporcionando cada vez mais a multiplicidade de canais para levar mensagens adequadas e possibilitar que toda a complexidade que absorve a área de saúde seja progressivamente desnudada pelos cidadãos. E, no sentido inverso, apresentar os meandros que cercam jornais, revistas, rádios e tevês para os profissionais de saúde, no caso a clientela interna.

Algumas experiências em determinadas realidades regionais hoje são alentadoras e comprovam que é possível avançar através de espaços diferenciados de atuação. Por exemplo: O projeto desenvolvido pela Universidade Federal de Uberlândia - MG - e o hospital universitário local através da criação de manuais com dicas essenciais para o esclarecimento das atividades de jornalistas e profissionais de saúde tem resultado em novas formas de entendimento entre os setores. 
O cientista, o jornalista e o assessor. Uma análise dos embates, dos limites e das possibilidades de construção de um possível diálogo

Outro exemplo: a elaboração da cartilha ilustrada, pelo Departamento de Comunicação da Universidade Federal de São Paulo, Unifesp, que aborda de maneira divertida a complicada relação dos médicos com a imprensa. A criação de vários serviços de atendimento ao usuário nos setores de saúde das secretarias, postos e hospitais é uma demonstração clara que o cidadão "redescobriu"seus direitos e tem buscado 'todos os caminhos possíveis para interagir com as instituições e empresas.

Infelizmente são casos isolados, mas que apontam para possibilidades de uma mediação eficaz e consequente para a saúde coletiva.

\section{Considerações finais}

Através de mediações conscientes, é possível trilhar novos caminhos para um dos dilemas apresentados pela professora Cremilda Medina, para quem a ciência e as condições sociais do final do século estão diante de um grande dilema: reafirmar o paradigma cientificista ou exigir uma nova mentalidade de saber, que é justamente o que a autora defende. Esta "nova mentalidade' apontaria para uma "ruptura, onde os especialistas precisam reencontrar os elos perdidos, entre eles e as múltiplas sabedorias para, juntos, darem outras respostas aos impasses históricos"que se apresentam hoje.

Infelizmente, os agentes que ainda hoje detêm posições de mando e controlam grande parte das informações nas principais instituições do país, na prática, ainda estão longe de entenderem o que Medina caracteriza como a experimentação de "atos epistemológicos", que apontariam para uma aproximação do especialista e do detentor do saber daquele homem mais comum, para juntos encontrarem soluções para os problemas que os afetam.

Medina confia que uma "pesquisa de linguagem transformadora" poderia levar a esta aproximação, e aqui enfatizamos que a comunicação tem um amplo papel a desempenhar neste processo. È o que de certa forma já se concretiza em algumas situações da prática profissional, como citadas neste artigo. Mesmo que esporádicas, mas de todo, extremamente enriquecedoras.

O comunicador da saúde deve interagir, buscar a via de mão dupla, num processo abrangente de relações, estabelecer um processo dialógico entre ciência, imprensa e sociedade. Esse "artesão criativo do diálogo transformador da ciência e do saber cotidiano"talvez possa reverter a opinião um tanto pessimista de boa parte de nossa academia. 
É o momento do repensar o coletivo, onde instituições que lidam com o saber e reflexões em seus espaços estabeleçam uma aproximação definitiva com as organizações jornalísticas, através de projetos concretos e não com complexas elucubrações delirantes. É hora também de as empresas jornalísticas atuarem na promoção da saúde, em vez de assumirem apenas a posição de agentes de acusação e de denúncia. É hora, enfim, de promover a formação de profissionais de comunicação capazes de fazer esta mediação para o bem social.

Precisamos transpor de simples registros de verdade para verdadeiros registros de justiça.

\section{Referências}

Alves, W. (2011). O espetáculo do saber: Corpos, Imagens e Materialidades Médicas. Revista EPOS, (4). Rio de Janeiro: IMS.

Araújo, I. \& Cardoso, J.M. (2007). Comunicação e Saúde. Col. Temas do Saber. Rio de Janeiro: Fiocruz.

Bueno, W.C. (1995). Comunicação na Era da Qualidade. São Paulo: Contexto Comunicação e Pesquisa/Unimed Amparo.

Bueno, W.C. (1996). Comunicação para a saúde: uma experiência brasileira. São Paulo: Ed. Plêiade/Unimed Amparo.

CRESCE a rejeição a governos na saúde, diz Datafolha. São Paulo: Portal UOL, disponível em www1.folha.uol.com.br, acesso em 31/01/2012.

Cunha, J.P. (1994). Um arsenal usado de forma conservadora. Revista Radis. Rio de Janeiro: Fiocruz.

Hansen, J.H. (2004). Como entender a saúde na comunicação?. São Paulo: Paulus.

Lopes, B. \& Nascimento, J. (1996). Saúde e imprensa: o público que se dane. Rio de Janeiro: Mauad.

Luiz, O.C. (2006). Ciência e risco à saúde nos jornais diários. SP: Anablume.

Malinverni, C. (2011). Epidemia Midiática: Um estudo sobre a construção de sentidos na cobertura da Folha de S.Paulo sobre a febre amarela, no verão de 2007-2008. Dissertação de Mestrado. São Paulo: USP. 
O cientista, o jornalista e o assessor. Uma análise dos embates, dos limites e das possibilidades de construção de um possível diálogo

Medina, C. (1994). Epistemologia Pragmática e Saber Plural. Coleção Saber Plural: Novo Pacto da Ciência, 3. São Paulo: ECA/USP/ CNPq.

Medina, C. (2003). A arte de tecer o presente, narrativa e cotidiano. SP: Summus editorial.

Neves, T. (2012). HIN1 e Produção de Sentidos na Mídia: A epidemia de 2009 nas páginas de O Globo, Extra e Expresso. Dissertação de Mestrado. Rio de Janeiro: Fiocruz.

Paes da Silva, M.J. (2002). Comunicação tem remédio: A comunicação nas relações interpessoais de saúde. São Paulo: Edições Loyola.

Paulino, F.O. (org). (2009). Comunicação e Saúde. Brasília: Casa das Musas.

RelatóRio anual do Sistema Nacional de Informações sobre Saneamento. Brasília: Ministério das Cidades. Disponível em www.snis.gov.br. Acesso em 31/01/2012.

Rothberg, D. (2011). Jornalismo Público. SP: Editora Unesp.

Tabakman, R. (2013). A saúde na mídia - Medicina para jornalistas, jornalismo para médicos. SP: Summus editorial. 